\title{
Foreign report
}

\section{A week in Zimbabwe}

\section{J. Piachaud, Honorary Senior Lecturer, Academic Department of Psychiatry, St Mary's Hospital, London W2 INY}

About five years ago I was seized by the idea of working in Africa. Now, nearing the end of a two year contract at the Department of Psychiatry, University of Zimbabwe, it is time to reflect.

In the patients there is a spiritual belief which looks to ancestral spirits to guide, heal and help through the possession of a medium who acts as the focus for their work. There is a belief in witchcraft which directs people to lay blame and look for culprits within their own community for any misfortune from sickness to failing exams.

To hear the voice of an ancestor is not necessarily a sign of madness, to struggle at night with ghosts may have meaning for that person and their family, to become possessed is an essential part of the belief system.

To determine what is "madness" and what has validity is sometimes difficult, but madness has its behavioural definitions; to be bewitched or hear the word of a spirit may be normal, but to run amok because of this needs treatment.

My clinical base is Harare Central Hospital, the older of the two hospitals in Harare. There are three consultants supported by four SHOs and a registrar. Over half my patients speak English and the nursing staff ably interpret for those who do not.

On Monday at 8.00 am the psychiatric out-patient clinic starts. A young man of 21 sits before me. The

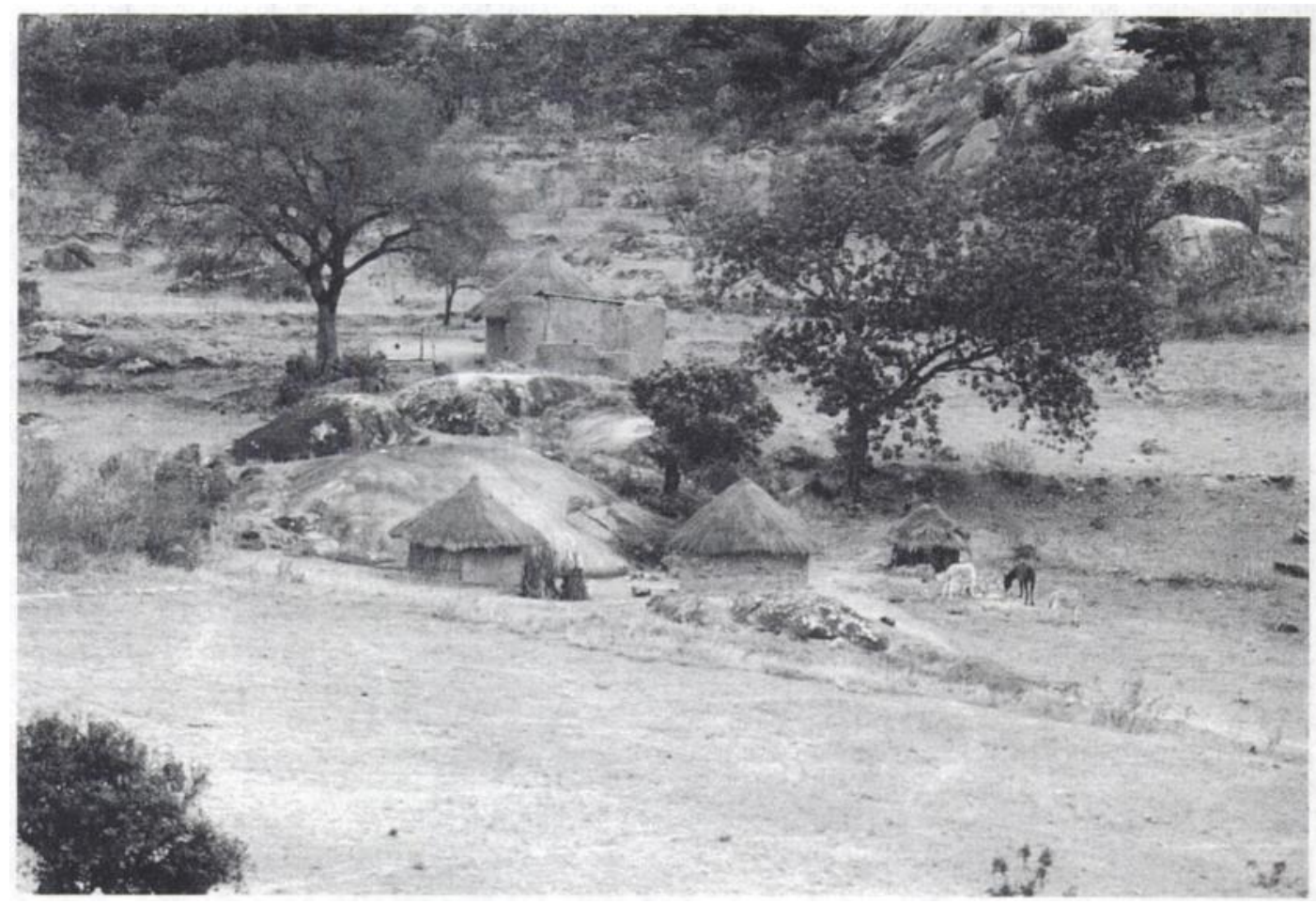

A typical family dwelling place in a rural area. 
message on his card simply reads "Diagnosis Schizophrenia, treatment Fluphenazine $25 \mathrm{mg}$ monthly, CPZ (chlorpromazine) $200 \mathrm{mg}$ BD."

Further enquiry reveals that he was in hospital once with vague psychotic symptoms, feeling he was bewitched; he was drinking heavily, unemployed, failed his ' $O$ ' levels six months before admission; he has remained quite well for ten months. Is this really schizophrenia? I could spend an hour with this patient and then ask the social worker to talk to his family but I only have ten minutes and the social worker has no means of transport. I start a reduction of his medication and as we discuss this he looks relieved. Next!

Two patients are brought in from a provincial hospital, having travelled over 100 kilometers by ambulance. The letters are identical ..."Violence... Old psychiatric patients ..." A brief interview tells me that they are both psychotic; we always admit such people to support the outlying hospitals. Next!

An 18-year-old girl is referred from the medical wards having taken 20 Chloroquine tabs after a row with her boyfriend; she seems regretful, her mother is with her, I refer her to a psychologist for counselling. Next!

Three of us may see 90 or more patients in this clinic.

The unit is a two acre site surrounded by a barbed wire fence, tucked at the corner of the hospital. The admission ward is an old police block; there is a two storey building with 40 closely packed beds on each floor; there is a dining room, a small conference room, an OT hut, and a block of four offices.

Between 70 and 100 patients stay here for varying times. There are no long stay places but the revolving door sometimes spins like a top. On a busy day we have over ten admissions of acutely disturbed people to our unit, some brought by police in handcuffs and leg irons, some in ropes by their relatives. The average length of stay is about 20 days and last year there were 1,600 admissions.

This fast turnover is achieved by large doses of neuroleptics, (no ECT) and tolerant families who accept back relatives once the acute phase is over. The diagnoses are varied, the major psychoses being responsible for much of this morbidity, with alcohol and cannabis well represented as associated factors.

There are shortages of drugs, equipment, maintenance, cars, amubulances, services and personnel which apply to all areas of the service. The root of this is a lack of hard currency which takes time to understand but is crucial to the situation. This is the Third World; it has not got the buying power to meet its needs.

On Tuesday and Thursday there are ward rounds with the SHOs and the students. We have 14 students at a time shared between four firms; they come for six weeks in their fourth year, the annual intake being 80 .

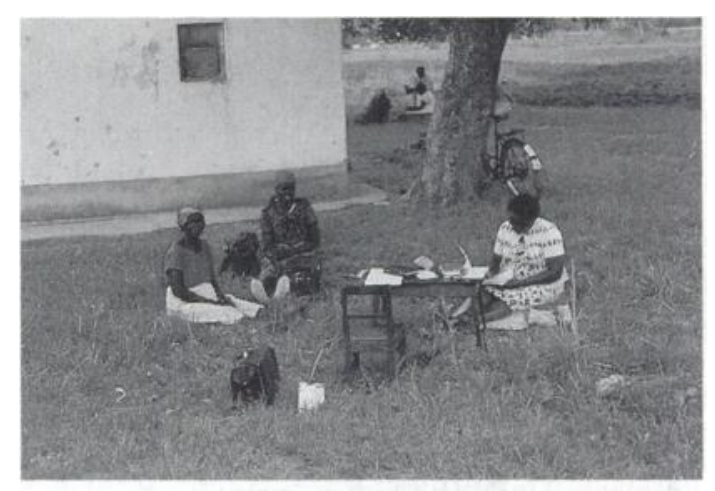

The psychiatric sister running a screening clinic for epilepsy.

Wednesday is departmental day so we meet at $8.15 \mathrm{am}$ for an academic presentation and later there is a case conference and time for us to meet informally. The Professor holds regular Departmental meetings to discuss teaching, research and service development.

The University has good access to foreign exchange. The libraries are well stocked, and teaching equipment and computers are readily available.

Friday is my research day. We have set up a project 100 kilometers from Harrare asking village health workers to identify people with epilepsy. Leaving the commercial farms around Harare, the neat fields give way to the open grass land of a communal area; $(60 \%$ of the population lives in communal farming areas.) Mud-walled, thatch-roofed rondavels come into view, each cluster representing a family unit; these in turn are grouped into loosely arranged villages of the extended family around which there are fields of maize and sunflower. A herd of cattle gaze indifferently at our passing; the young boys tending them wave cheerfully to us.

Some way up a dirt track we reach the school where we have agreed to meet the village health workers. The arrival of a university doctor and two nurses attracts a lively crowd and setting up clinic under a tree we review the complaints which are many: backaches, headaches, dizziness, some severe depressions, some psychoses, some people mentally retarded.

We see a few with epilepsy which more than most illnesses is seen as having spiritual causes which stigmatise the family.

Making a home visit on a psychiatric patient, we are led into a thatched kitchen which is cool and remarkably free from smoke despite a central fire for cooking. A man of 23 is brought to us. He has not spoken for three weeks, he avoids eye contact and shows some mild waxy flexibility; this is his third illness; in the past he has heard voices and become excited. 
The family tell him I am a doctor from the University but he is unimpressed. We learn that he is not eating, taking his medication, going to the toilet and is no bother. The family is not harsh with him. As we go I see him look from under his eyebrow at the strange little party which intruded on his personal space.

Trips out of Harare are quite beyond my usual experience. The district we visit is one of the more fertile, but there are places which are dry, where malnutrition and malaria are rife, where it is 20 kilometers to the nearest clinic where one nurse serves 10,000 people and the nearest hospital is 100 kilometers on a dust road, where one doctor may serve over 100,000 people.

Over the weekend I retreat to a first world lifestyle in our university house, with our fridge, our television, our maid. Harare is a beautiful city with a perfect climate. We shop in well stocked supermarkets, the children are well schooled, the restaurants and cinemas cater for all tastes.

What shall I achieve in the third world? It will not be much but it has been important to look; not just the glance of passing through, but time to stare and get under the sense of order and over the disbelief that such poverty can coexist with such wealth; to see the value of the extended family and of the lack of grasping expectation

It is good fun to practise psychiatry here; I would recommend it strongly. There is good opportunity for service and research but a lot of frustration if you expect too much; even more than at home I feel like a voyeur. Perhaps the only achievement is coming and spending time here, everything else is ephemeral. To come, make relationships, however fleeting, that sense of human fellowship; these things have the most value.

\title{
Conference briefings
}

\section{National Health Service funding for trainee child psychotherapist posts}

\author{
STEPhen IsaACs, Consultant in Child and Adolescent Psychiatry, Waltham Forest \\ Health Authority Child and Family Consultation Service, Shernhall Street, \\ London E17 3EA
}

The Jubilee Room at the House of Commons on November 5 th would seem a suitably explosive venue to launch a campaign to obtain organised funding for trainee child psychotherapy posts. A working lunch was sponsored by the Child Psychotherapy Trust and the Association of Child Psychotherapists, and hosted by Emma Nicholson, MP, a Vice-Patron of the Trust.

The proceedings were opened by Joan Lestor, MP. She pointed out that the Cleveland Report, the Children Act and The Health of the Nation all stress the need for prevention and treatment in children with emotional disturbance; although sexual abuse and physical abuse receive a higher profile, emotional abuse can be equally damaging.

The Chair of the Child Psychotherapy Trust, Dilys Daws, emphasised the urgent need for psychotherapy for children, describing theirs as a lesserdeveloped profession. There are currently just over
240 child psychotherapists working within the UK and a further 70 students; the vast majority of these are concentrated in the London area, with only two in Scotland and one in Wales. Ms Daws pointed out that theirs is the only profession in the NHS who have to fund their own training, despite psychotherapists being vital specialist members of multidisciplinary teams. There is a lack of organised funding and the average cost of training a child psychotherapist is $£ 24,000$ spread over four years. The campaign aims to secure funding that will allow the training of an additional 250 therapists over the next ten years, at a cost of $£ 12$ million a year at 1991/92 prices.

Miranda Feuchtwang, Chair of the Association of Child Psychotherapists, supported these aims and informed the meeting of a new training school in Scotland and a provisional training school being set up in Birmingham. 